\title{
Effect of In-service Training Program on Nurses' Performance Regarding Patients with Whipple Surgery
}

\author{
Asmaa Mahmoud Gomaa ${ }^{1}$, Magda Ahmed Mohamed ${ }^{2}$, Ahmed Mohamed Ibrahim ${ }^{3}$ \& Ghada Hassan Ahmed ${ }^{4}$. \\ ${ }^{1 .}$ Demonstrator of Medical-Surgical Nursing Department, Faculty of Nursing, Assiut University, Egypt. \\ 2. Professor of Medical-Surgical Nursing Department, Faculty of Nursing, Assiut University, Egypt. \\ ${ }^{3 .}$ Lecturer of General surgery, Faculty of Medicine, Assiut University, Egypt. \\ ${ }^{4 .}$ Lecturer of Medical-Surgical Nursing Department, Faculty of Nursing, Assiut University, Egypt.
}

\begin{abstract}
Background: In-service training program for nurses has a vital role in developing and enhancing the skills required to provide high standards of care.The current study aimed to evaluate the effect of implementing in-service training program on nurses' performance regarding patients with Whipple surgery. Research design: A quasiexperimental research design (pre-post test) was used to conduct this study. Setting: Surgery department of ALRajhi Liver Hospital at Assiut University. Sample: A convenience sample of 30 nurses working in the surgery department. Tools: Pre/post structured interview questionnaire for assessment nurses knowledge and Observational checklist sheet for assessment nurses performance were used. Results: Marked improvement in nurses'knowledge and practice regarding care of patients with Whipple surgery after implementation of in-service training program with statistical significant difference P. value $<0.001 * *$. The study finding also clarified that there was a statistically significant relationship between knowledge and practice post-implementation of the program Conclusion: According to the study findings, it can be concluded that the implementation of in-service training program had improved nurse's knowledge and practice regarding patient with Whipple surgery. Recommendation: Continuous implementation of in-service training courses to make nurses upgraded about nursing information regarding care of patients with Whipple surgery.
\end{abstract}

\section{Keywords: In-service Training Program, Nurses 'performance \& Whipple surgery.}

\section{Introduction}

Pancreatoduodenectomy, or Whipple surgery, is one of the most common forms of pancreatic surgery. The procedures encompass the removal of the biliary gland, the resection of a part of the stomach, duodenum, biliary drainage, and pancreas. Afterward, the structures are reassembled where the remaining parts of the stomach, pancreas, and bile duct are attached to numerous parts of the jejunum (Leung $\boldsymbol{\&}$ Buscaglia., 2019).

Pancreatic cancer is that the seventh leading reason for cancer-related deaths worldwide and is that the fourth leading reason for cancer death in men, and also the fifth in women ( Rawla et al., 2019). Because it is notoriously resistant to treatments like radio-chemo- and immunotherapy, surgical treatment using (PD) remains the mainstay and offers the only chance of long-term survival.

Patients undergoing pancreaticoduodenectomy are in danger for a variety of adverse postoperative complications, including generic complications like surgical site infection (SSI), procedure-specific complications such as postoperative pancreatic fistula (POPF), delayed gastric emptying (DGE), postoperative hemorrhage and diabetes mellitus, and other complications like malabsorption and vitamin and mineral deficiencies (Nahm et al., 2018).

Nurses are the health team members who spend the foremost time with the patient after Whipple surgery, giving them care and had an essential role as educators in the different learning needs and demands so, the supply of them with a training program is crucial. In-service training incorporates a set of measures taken to promote empowerment and competency among nurses for the better undertaking of their tasks, thus helping the organization to attain its goals. In-service training serves to upgrade the staff's occupational knowledge and professional skills and improve the best practices for fulfilling various tasks and responsibilities (Chaghari et al., 2017).

\section{Significance of the study}

From the researcher's experience during 2years of the training period in the surgery department of AL-Rajhi Liver Hospital at Assiut University, it has been noted that most of the nurses hadn't sufficient experience in dealing with the patient after surgery. In addition to the fact that the operation has serious complications so the nurse should have the skill in caring for patients to avoid these complications. 
Hence the necessity for in-service training programs to promote the nurses' knowledge that might help them to contribute a successful patient care outcome.

\section{Operational definitions}

Whipple surgery: also known as pancreatoduodenectomy, is the most common surgery for the removal of tumors of the head of the pancreas, ampulla, distal common bile duct, or periampullary duodenum (Shi \& Basturk, 2019).

In service training program: is a professional training or staff development effort, where professionals are trained and discuss their work with others in their peer group (Khan et al., 2018).

\section{Aims of the study}

The present study was undertaken in order to evaluate the effect of implementing an in-service training program on nurses' performance who caring of patients with Whipple surgery.

\section{Research Hypothesis}

1. The mean knowledge scores of the nurses under study will be improved post the implementation of the in-service training program about Whipple surgery.

2. The mean practice scores of the nurses under study will be improved post the implementation of the in-service training program about Whipple surgery.

3. A positive relation will exist between knowledge and practice scores obtained by nurses who receiving in-service training programs.

\section{Subjects \& Methods \\ Research design}

A quasi-experimental research design (pre-post test) was used to conduct this study.

\section{Setting:}

The study was conducted in the surgery department of AL-Rajhi Liver Hospital at Assiut University.

\section{Study variables}

- The independent variable was designed in-service training program.

- The dependent variable was nurses'performance.

\section{Sample}

A convenience sample of 30 nurses working in surgery department and who are willing to participate in the study.

\section{Tools for data collection}

Two tools were used in this study:

Tool (I) Pre/post structured interview questionnaire for nurses: It was developed in a simple clear Arabic language by the researcher based on a literature review and experts' opinions in the light of pertinent references to assess nurses' knowledge. It consists of two parts:
Part (I): Demographic characteristics of the studied nurses such as age, sex, level of education, years of experience, and previous training courses.

Part (II): Nurses' knowledge regarding care of patients with Whipple surgery. It includes 35 questions and covering the following points.

- Nurses' knowledge regarding anatomy and function of the pancreas, which includes the anatomy of the pancreas, functions of the pancreas, diseases of the pancreas, treatment of pancreatic cancer.

- Nurses' knowledge regarding Whipple surgery, which includes a definition of Whipple surgery, indication, contraindication, complications, signs of infection, signs of delayed gastric empty, and signs of pancreatic fistula.

- Nurses' knowledge regarding nursing care for patients, which includes how to manage pain, bleeding, elevated blood sugar, and diarrhea.

Scoring system: Nurses' knowledge regarding patients with Whipple surgery included 35 questions. Eleven of the questions were in multiple-choice questions, and twenty-four were open questions. Multiple-choice questions were scored as (correct $=2$, incorrect $=0$ ). The open questions were scored as (correct $=2$, incomplete correct $=1$, incorrect $=0$ ). The scores of items were summed-up and then converted into a percent score. Those who obtained $(<75 \%)$ were considered having unsatisfactory levels. While those who obtained $(\geq 75 \%)$ were considered having a satisfactory level.

Tool (II): Observational checklist sheet: It was conducted to assess nurses' practice regarding the care of patients postoperatively. It was designed by the researcher according to literature review. It was adopted from (Perry et al, .2019; Stein\& Hollen, 2020; Yoost\& Crawford, 2019; Dougherty\& Lister, 2015). The researcher will assess nurses' practice before and after the program regarding the following procedure:

- Hand washing.

- Dressing application for closed surgical wounds.

- Care of the drains.

- Nasogastric tube insertion.

- Nasogastric tube irrigation.

- Nasogastric tube removal.

- Measuring blood glucose by finger stick.

Scoring system: Each item in the checklist was scored as follows: - (Done correct=2, done incorrect $=1$, and not done $=0$ ). Scores of more than 75 $\%$ are regarded as an adequate level of practice. Scores of less than $75 \%$ are regarded as an inadequate level of practice. 


\section{Procedure}

The study was conducted in three phases (preparatory phase, implementation phase, and evaluation phase).

Phase (1): the Preparatory phase included the following:

Reviewing current national and international related literature regarding Whipple surgery using books, articles, and the internet was done to design the study tools for data collection.

\section{Content validity and reliability}

Once the tools of data collection were prepared, their face validity and content validity were judged by a panel of five experts (three professors of medical surgical nursing and two professors of general surgery), who revised the tools for clarity, relevance, applicability, comprehensiveness, and ease of implementation. In light of their assessments, minor modifications were applied.

The reliability of the two tools was measured by Cronbach's alpha coefficient test.

Official permission was obtained from the director of AL-Rajhi liver hospital to conduct the study.

Pilot study: A pilot study was carried out on five nurses to test for clarity, applicability, and ease of implementation. The results of the data obtained from the pilot study helped in the modification of the tools.

- The designed in service training program was developed, after an intensive literature review considering nurses 'needs and their levels of understanding.

- Teaching materials were prepared.

Phase (2): The implementation phase:

- Data were collected from the surgery department of AL-Rajhi Liver Hospital at Assiut University Hospital during the period from Feb.2020 to Sept. 2020.

- At the initial interview, the researchers introduced herself and explain the nature \& purpose of the training program to nurses who whiling to participate.

- Assessment of the nurses'knowledge using (tool I) that filled by nurses.

- Assessment of the nurses'practice through direct observation using (tool II) that filled by the researcher.

- The study was carried out in the morning and afternoon shifts.

- A designed training program was conducted through three theoretical sessions and three practical sessions and the duration of each session was from 30 to 45 minutes.

- The program was given within three days every week and every session was given two times (one session in the morning and the other session in the afternoon).
- The program was repeated three times because nurses were divided into small groups (5nurse for each morning and afternoon group).

- Every nurse was supplemented with a manual booklet in the Arabic language.

- Small group discussion and demonstration were used to conduct the training program for nurses, in addition to teaching aids such as PowerPoint and Video were used.

- For the theoretical part: the first session was included the objectives of the training program, anatomy, and function of the pancreas, diseases of the pancreas.

Whipple surgery definition, indication, contraindication, and complications were the component of the second session. The third session was composed of nursing care for a patient with Whipple surgery.

By the end of the theoretical part, the practical part was conducted.

For the practical part: the first session was included the following procedures hand washing, applying a wound dressing, and care of wound drains. The second session was composed of how to perform nasogastric tube insertion, nasogastric tube removal, and nasogastric tube irrigation. The third session was composed of how to measure blood glucose by finger stick and discuss any misunderstanding of the previous procedure with nurses.

Each session was started by a brief revision of the previous session and was ended by a discussion of the current session.

\section{Phase III: The evaluation phase}

After the implementation of the training program, an evaluation of the effectiveness of the training program was done by reassessing and comparing the level of nurses'knowledge and practice pre and post implementing of the training program. An evaluation of the training program was done immediately by the end of the program implementation.

\section{Ethical considerations}

The research proposal was approved by the Ethical Committee within the Faculty of Nursing. There was no risk for study subjects during the application of the research. The study was following common ethical principles in clinical research. Oral consent was obtained from the nurses that were willing to participate in the study, after explaining the nature and purpose of the study. The confidentiality of the subject data was assured.

They informed that participation was voluntary and that nurses could withdraw at any time of the study. Anonymity was considered during the collection of data. 


\section{Statistical analysis}

- The data entry and data analysis were done using (SPSS Ver.23.).

- Descriptive statistics (number, percentage, mean and standard deviation) were done.

- Chi-square test had been done to compare between qualitative variables before and after the program.
- Independent sample t-test had been done to compare between quantitative variables before and after the program.

- P-value was considered statistically significant when $\mathrm{p}<0.05$.

\section{Results}

Table (1): Frequency and percentage distribution for demographic characteristics of studied nurses $n=30$

\begin{tabular}{|c|c|c|}
\hline Demographic data & $\mathbf{N}$ & $\%$ \\
\hline \multicolumn{3}{|l|}{ 1. Age } \\
\hline - 20-25 years & 4 & 13.3 \\
\hline - 25-30 years & 17 & 56.7 \\
\hline - >30 years & 9 & 30.0 \\
\hline - Mean \pm SD (range) & \multicolumn{2}{|c|}{$29.20 \pm 3.633(20-39$ years $)$} \\
\hline \multicolumn{3}{|l|}{ 2. Gender: } \\
\hline $\begin{array}{l}\text { - Male } \\
\text { - Female } \\
\end{array}$ & $\begin{array}{c}1 \\
29 \\
\end{array}$ & $\begin{array}{c}3.3 \\
96.7 \\
\end{array}$ \\
\hline \multicolumn{3}{|l|}{ 3. Education level: } \\
\hline $\begin{array}{l}\text { - Diploma } \\
\text { - Instituted of nursing } \\
\text { - Bachelor }\end{array}$ & $\begin{array}{c}4 \\
20 \\
6 \\
\end{array}$ & $\begin{array}{l}13.3 \\
66.7 \\
20.0\end{array}$ \\
\hline \multicolumn{3}{|l|}{ 4. Years of experience: } \\
\hline $\begin{array}{l}\text { - less than five years } \\
\text { - more than five years } \\
\end{array}$ & $\begin{array}{c}7 \\
23 \\
\end{array}$ & $\begin{array}{l}23.3 \\
76.7\end{array}$ \\
\hline \multicolumn{3}{|c|}{ 5. Previous training courses about Whipple surgery: } \\
\hline $\begin{array}{l}\text { - No } \\
\text { - Yes } \\
\end{array}$ & $\begin{array}{c}26 \\
4 \\
\end{array}$ & $\begin{array}{l}86.6 \\
13.3 \\
\end{array}$ \\
\hline \multicolumn{3}{|l|}{ 6. Previous General training courses: } \\
\hline $\begin{array}{l}\text { - No } \\
\text { - Yes }\end{array}$ & $\begin{array}{l}11 \\
19\end{array}$ & $\begin{array}{l}36.7 \\
63.3\end{array}$ \\
\hline
\end{tabular}

Data described as (no\& \%) chi-square and mean \pm SD independent sample t-test.

Table (2): Comparison between level of knowledge score obtained by nurses pre\& post implementing of training program $(n=30)$.

\begin{tabular}{|c|c|c|c|c|c|}
\hline \multirow{2}{*}{ Knowledge level } & \multicolumn{2}{|c|}{$\operatorname{Pre}(\mathbf{n}=30)$} & \multicolumn{2}{|c|}{ Post $(n=30)$} & \multirow{2}{*}{ P. value } \\
\hline & No. & $\%$ & No. & $\%$ & \\
\hline Unsatisfactory & 29 & 96.7 & 2 & 6.7 & \multirow[t]{2}{*}{$0.001 * *$} \\
\hline Satisfactory & 1 & 3.3 & 28 & 93.3 & \\
\hline Mean \pm SD & \multicolumn{2}{|c|}{$32.86 \pm 9.29$} & \multicolumn{2}{|c|}{$63.8 \pm 6.74$} & $0.001 * *$ \\
\hline
\end{tabular}

Independent T-test** significant difference at $p$. value $<0.001 * *$

Table (3): Comparison between level of practice score obtained by nurses pre\& post implementing training program $(\mathbf{n}=30)$.

\begin{tabular}{|c|c|c|c|c|c|}
\hline \multirow{2}{*}{ Practice level } & \multicolumn{2}{|c|}{$\operatorname{Pre}(\mathbf{n}=30)$} & \multicolumn{2}{|c|}{ Post(n=30) } & \multirow{2}{*}{ P. value } \\
\hline & No. & $\%$ & No. & $\%$ & \\
\hline Inadequate & 20 & 66.7 & 0 & 0 & \multirow[t]{2}{*}{$0.001 * *$} \\
\hline Adequate & 10 & 33.3 & 30 & $100 \%$ & \\
\hline Mean \pm SD & \multicolumn{2}{|c|}{$117.50 \pm 28.43$} & \multicolumn{2}{|c|}{$193.06 \pm 12.94$} & $0.001 * *$ \\
\hline
\end{tabular}

Chi-square test ${ }^{* *}$ significant difference at $p$. value $<0.001$ - Independent $T$-test ${ }^{* *}$ significant difference at $p$. value $<0.001$ 


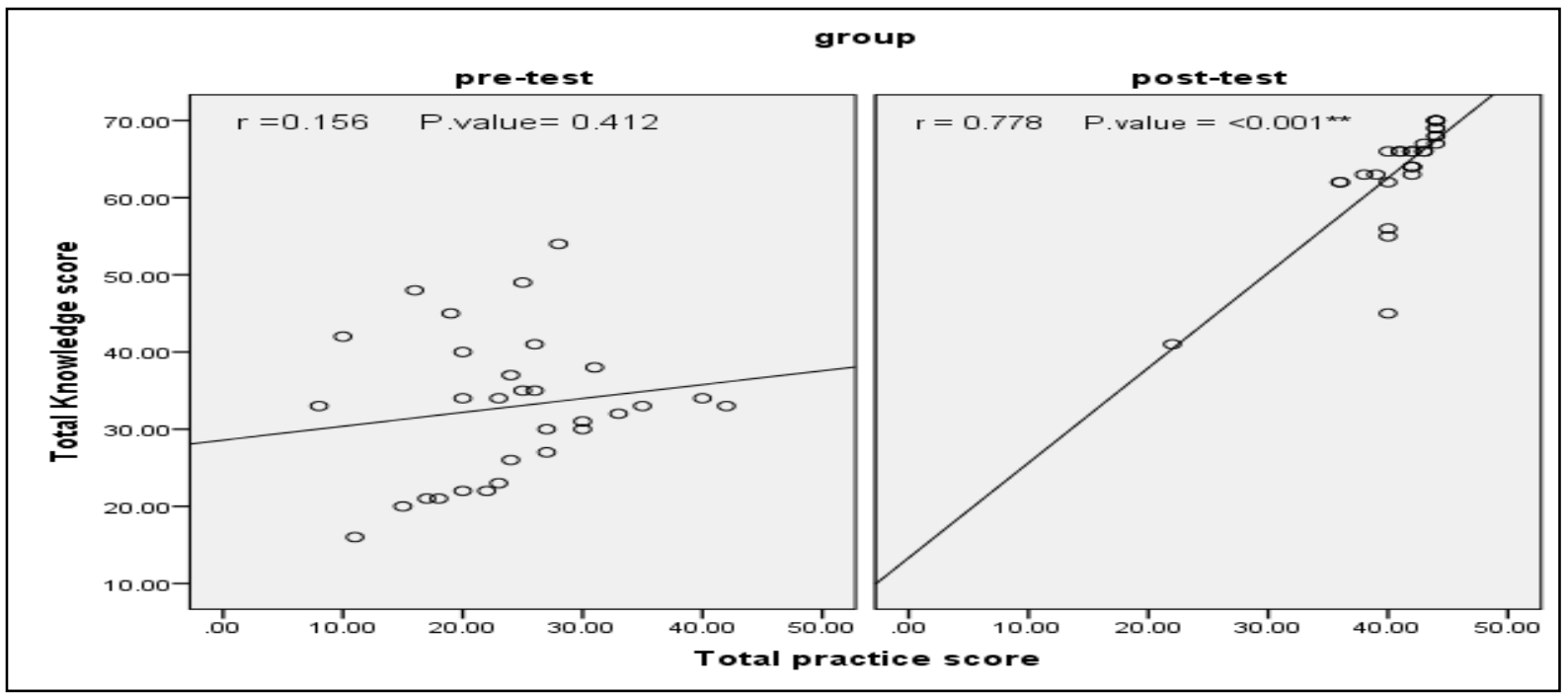

Fig (1): Correlation between nurses'knowledge and practice pre\& post-test

Table (1): Showed that, more than half of nurses were aged from 25 to 30year and most of them were female $(96.7 \%)$. More than half of nurses had Nursing Technical Institute $(66.7 \%)$ and the majority of them $(76.7 \%)$ their year of experience more than 5years. less than one-third of nurses had attended training courses about Whipple surgery $(13.3 \%)$ while more than half of them $(63.3 \%)$ had attended general training courses.

Table (2): Showed that, the most of nurses had an unsatisfactory level of knowledge pre implementing training program while, the most of nurses had a satisfactory level of knowledge in post implementing training program $(93.3 \%)$ with $\mathrm{p}$. value $0.001 * *$.

Table (3): Demonstrate that, most nurses had an adequate level of practice in post implementation of the training program $(96.7 \%)$ with p. value $0.001 * *$.

Fig (1): Illustrates that, a positive significant statistical correlation between knowledge score and practice score post - test while, pre-test there was no significant correlation between knowledge and practice score.

\section{Discussion}

Among common cancers, pancreatic cancer has one of the poorest prognoses. Pancreatic cancer is notoriously difficult to diagnose in its early stages. As it were around $20 \%$ of pancreatic cancer patients are qualified for Whipple surgery. The Whipple surgery includes removal of the "head" of the pancreas, the duodenum, a portion of the common bile duct, gallbladder, and in some cases portion of the stomach (Alkattan, 2018). Delayed gastric empty, a pancreatic fistula, hemorrhage, diabetes mellitus or glucose intolerance, malabsorption and vitamin and mineral deficiencies are the foremost common complications experienced post-Whipple surgery. (Nahm et al., 2018).

The present study showed that, more than half of nurses had Nursing Technical Institute. Less than one-third of nurses had attended training courses about Whipple surgery and more than half of them are attended general training courses. This result agrees with (Mobed, 2016) who stated that the majority of nurses had nursing technical institute. More than half of them had general training courses and less than one-third of them had in-service training courses related to paracentesis procedure.

The result also showed that, most of the nurses were female, aged from25-30years. This result agrees with (Mohamed, 2018) who stated that the majority of nurses were female, at the age group less than 30 years and most of them have years of experience of more than5 years. This does not agree with (Abdulatif, 2016) who stated that, the majority of nurses were aged from 20-45 years; also the majority of nurses were males.

The current study showed that, most of the nurses had an unsatisfactory level of knowledge related to the anatomy of the pancreas, Whipple surgery, and nursing care for patients with such type of surgery before conducting of the training program. From the researcher opinion, this might be due to the most of the nurses believe that knowledge related to Whipple surgery is the responsibility of the physician, an only small number of them who received training courses about Whipple surgery, lack of pre-employment courses, and nurses rotation from department to other without orientation program affect nurses' level of knowledge negatively.

This results congruent with (Mohammed, 2019) who found that, the majority of nurses had unsatisfactory 
level of knowledge about acute pancreatitis, this might be related to the fact that all nurses were not receiving any previous training program about acute pancreatitis, their knowledge received during undergraduate were not upgraded, with no preemployment orientation program and shortage of nurses caring for such group of patients.

The study finding also revealed, a great improvement in studied nurses knowledge immediately after implementation of the training program with ( $\mathrm{P}$. $\left.\mathrm{v}<0.001^{* *}\right)$.From researcher openion, this was due to the refreshment of nurses knowledge through the program sessions, the simple language of the booklet, and increase nurses motivation to learn and update their knowledge.

This finding is in agreement with (Mohamed et al., 2019) who documented that after implementation of the training program it was observed that the majority of nurses show significant improvement in the nurse's knowledge about anatomy and physiology of the liver with $\mathrm{P}$. value $<0.001 * *$

We concluded that the in-service training program has an essential role in improving nurses' level of knowledge. This was in the same line with (Ahmed \& Dutta, 2016) who reported that nurses' level of knowledge significantly improved after the training program, also it is congruent with (Mobed, 2016) who stated that educational program significantly influenced the nurses' performance.

Regarding the nurses' practice, the study finding showed that, the majority of nurses had an unsatisfactory level of practice before the implementation of the training program. From the researcher's point of view this might be related to lack of training pre-employment so newly graduated nurses learn from old nurses and take their experience from them correct true or not correct. This result in the same line with ( Mohamed et al,.2019) who found that, the majority of nurses didn't apply most of the steps about caring for a patient with hypoalbuminemia after liver transplantation.

The current results revealed that, there were highly statistically significant improvement in practice level regarding nursing care for patient with Whipple surgery when compared with pre and post of implementation of the in-service training program with $\left(\mathrm{p}<0.01^{* *}\right)$. This comes in the same line with (Ahmed et al., 2019) who found that statistically significant improvements in the nurses level of knowledge was observed immediately after implementation of the training program and a sharp improvement in nurses skills, with a statistically significant difference.

Regarding, the relationship between nurses' knowledge and practice. The findings of this study clarified that, there was a positive correlation between nurses' knowledge and practice scores. This reflects that the nurse who has enough base of knowledge, able to acquire an adequate level of practice for patient care. This in the same line with, (Salgado, 2010) who illustrated that nurses should maintain a high level of knowledge and practice in caring of such group of patients and must gain knowledge before they enter practice.

\section{Conclusion}

Based on the result of current study, it can be concluded that:

- The mean knowledge scores of the nurses under study have been improved post the implementation of the in-service training program about Whipple surgery.

- The mean practice scores of the nurses under study have been improved post the implementation of the in-service training program about Whipple surgery..

- There was a positive correlation between the nurses' level of knowledge and practice after implementation of in-service training program.

\section{Recommendations}

Based on the results of current study, it can be suggested that:

- Providing nurses with updated booklets to the refreshment of their knowledge about Whipple surgery to improve their level of knowledge.

- Continuous implementation of in-service training courses to updated nurses about new nursing care issues that reflect positively on nurses' performance.

\section{References}

- Abdulatif N., (2016): Effect of an Educational Program on Nurses' Knowledge and Practice regarding Emergency Medications, Master degree, Critical care Nursing department, Faculty of Nursing, Assiut University, discussion part Vol.(10), No.(3): Pp.89-95.

- Ahmed N., Dutta S., (2016): Effectiveness of planned Teaching Program on nurses' knowledge and practice Regarding Glasgow Coma Scale for Neurological Clients of a Selected Hospital, Kolkata, American Journal of Nursing Science,Vol.(11), No.(12): Pp.122-125.

- Ahmed, G., Azer, S., \& AbdEl-all, H., (2019): Effect of In-service Training Program on Minimizing Nursing Intravenous Medication Process Errors by Syringe Through Intravenous Catheter, American Journal of Nursing Science, Vol. ( 8), No.(4) :P. 153.

- Alkattan, A., (2018): Whipple Procedure for Locally Invasive Pancreatic Cancer: Complications 
vs. Survival, EC Gastroenterology and Digestive System, Vol. (9), No. (5):Pp. 459-460.

- Chaghari M., Saffari M., Ebadi A., \& Ameryoun A., (2017): Empowering education: A new model for in-service training of nursing staff, J Adv. Med Educe Prof, Vol. (5), No. (1): Pp 26-32.

- Dougherty, L., \& Lister, S., (Eds.). (2015): The Royal Marsden manual of clinical nursing procedures, hand washing,ch3,eighth ed., John Wiley \& Sons, Pp.61-63.

- Khan R., Khan F., \& Khan M., (2018): Impact of training and development on organizational performance. Global Journal of Management and Business Research. Vol. 11, No. (7): P p. 8-63.

- Khorana, A., Potentially curable pancreatic cancer (2017): American Society of Clinical Oncology Clinical Practice Guideline Update. J. Clin. Oncol, Vol. (19), No. (5): Pp. 2324-2328.

- Perry, A., Potter, P., Ostendorf, W., \& Cobbett, S., (2019): Canadian Clinical Nursing Skills and Techniques, E-Book., Performing Wound Dressing, 1st ed, Canada, Elsevier Health Sciences: P.p10801089.

- Salgado F., Vianna L., Giavoni A., Melo G., Karnikowski M., (2010): Hypoalbuminemia terapia medicamentosa no prognóstic odeidosos hospitalizados, Rev Assoc Méd Bras., Vol.(56),No.(2):Pp .145- 150.

- Shi, J., \& Basturk, O., (2019): Whipple Grossing in the Era of New Staging: Should We Standardize? Diagnostics, vol (9), No. (4): P 132.

- Leung, G., \& Buscaglia, J., (2019): Pancreatic enzyme replacement therapy in post-Whipple patients: optimizing the dose and maximizing compliance, Clinical Gastroenterology and Hepatology vol. (19), No. (1):P. 671.

- McCarthy, K., Zhang, W., Soliz, J., \& Lovinaria, D., (2020): Pancreatic Surgery in Cancer Patients: Post-Surgical Care, Oncologic Critical Care, vol. (18), No. (3): Pp.1809-1823.

- Mobed, K., Makhlouf, N., \& Abd Almageed, A., (2016): Effect of Designed Nursing Guidelines on Nursing Intervention to Reduce Complications for Cirrhotic Patients Undergoing Paracentesis, Assiut Scientific Nursing Journal, Vol.(4),No.(8):Pp.33-45.

- Mohamed, A., Mohamed, M., \& Abdel Hafez, A., (2019): Effect of teaching program on nurses' performance about hypoalbuminemia after liver transplantation, Assiut Scientific Nursing Journal, Vol. (7), No. (18):Pp.114-121.

- Mohamed, H., Ibrahim, O., Mohamed, M., \& Mohamed, K. S. (2018). Effect of an Educational Program About Cell Salvage Machineon Nurses' Performance During Hepatobiliary Pancreatic Surgeries, Assiut Scientific Nursing Journal,Vol( 6),No.(14): Pp. 186-196.
- Mohammed, S., Mohammed, M., \& Mehany, M., (2019): Effect of Educational Program on Nurses' performance Regarding Patients with Acute Pancreatitis, Assiut Scientific Nursing Journal,Vol.( 7),No.(17): Pp. 64-74.

- Nahm C., Connor S., Samra J., Mittal A., Postoperative pancreatic fistula(2018): a review of traditional and emerging concepts. Clin Exp Gastroenterol, Vol.(7), No. (1): Pp105-18.

- Rawla, P., Sunkara, T., \& Gaduputi, V., (2019): Epidemiology of pancreatic cancer: global trends, etiology and risk factors. World journal of oncology, Vol.(10),No.(1):Pp. 778-783.

- Stein, L., \& Hollen, C., (2020): Concept-Based Clinical Nursing Skills E-Book: Fundamental to Advanced, Obtaining Capillary Blood Glucose Measurment, 1st ed, Canada, Elsevier, Pp151-155.

- Yoost, B., \& Crawford, L., (2019): Fundamentals of Nursing E-Book: Active Learning for Collaborative Practice,Hand Hyagiene, $2^{\text {nd }}$ ed, Elsevier Health Sciences,Pp487-488. 